\title{
Repeat injuries in childhood
}

\author{
S M Peters, ${ }^{1,2,3}$ MB ChB, BA, MMed, FCPHM (SA); M-A Davies, ${ }^{2,3}$ MB ChB, MMed, FCPHM (SA), PhD; A B van As, ${ }^{3,4}$ MBA, PhD, FCS (SA) \\ ${ }^{1}$ Executive Management, Groote Schuur Hospital, Cape Town, South Africa \\ ${ }^{2}$ Health Impact Assessment Unit, Western Cape Government: Health, Cape Town, South Africa \\ ${ }^{3}$ School of Public Health and Family Medicine, Faculty of Health Sciences, University of Cape Town, South Africa \\ ${ }^{4}$ Trauma Unit, Red Cross War Memorial Children's Hospital, Cape Town, South Africa
}

Corresponding author: S M Peters (shrikant.peters@westerncape.gov.za)

Background. Injury remains a leading cause of childhood morbidity and mortality in the developing world. The probability of injury occurrence is influenced by agent, host and environmental factors. Studies of repeat injuries in childhood therefore provide insight into factors in the epidemiological triad predisposing children to injury.

Objectives. To determine the proportion of children and the factors associated with repeat presentations to the Red Cross War Memorial Children's Hospital Trauma Unit (RCWMCH TU) in Cape Town, South Africa, for all non-transport-related injuries in childhood.

Methods. This was a retrospective cohort study using data from the RCWMCH TU. We included children aged 0 - 10 years with first presentation from January 1997 to June 2013 and followed up until the earlier of age 13 years or June 2016. We assessed individual and population-level factors associated with repeat injury using multilevel Poisson regression analysis. Child dependency ratios were derived from the 2011 National Census.

Results. Between 1997 and 2013, 72490 children aged <10 years (59\% male) presented to the RCWMCH TU for the first time with injuries. After the initial injury, 9417 (13\%) presented with a repeat injury by 2016 and before age 13 years. After adjusting for health subdistrict, distance from RCWMCH TU and age at first presentation, factors associated with reduced repeat presentation were injury identified as due to abuse (adjusted incidence rate ratio (aIRR) 0.6; 95\% confidence interval (CI) 0.4 - 0.7), fluid burn (aIRR 0.6; 95\% CI 0.6 - 0.7), foreign body ingestion (aIRR 0.7; 95\% CI 0.7 - 0.9), and moderate and severe (v. minor) initial injury (aIRR 0.9; 95\% CI 0.8 - 0.9 and aIRR $0.7 ; 95 \%$ CI $0.6-0.8$, respectively), while boys were more likely to have repeat injury presentations (aIRR 1.4; 95\% CI $1.4-1.5$ ).

Conclusions. Repeat presentations were substantial and associated with male gender. They occurred less commonly after fluid burn injuries, foreign body ingestion and moderate to severe injuries. Children with intentional injuries were also less likely to have a repeat presentation. Further research is indicated for childhood injuries with greater propensity to repeat, including non-height falls and sport-related injuries. Secondary injury prevention education should not neglect patients with unintentional and minor injuries. These results strengthen the hypothesis that injuries arise as a result of sustained exposure to agent, host and environmental risk factors.

S Afr Med J 2020;110(12):1218-1225. https://doi.org/10.7196/SAMJ.2020.v110i12.14546

Traumatic injury is a leading cause of morbidity and mortality in childhood. Globally, unintentional injuries alone account for $>830000$ child deaths annually. ${ }^{[1,2]}$ Injury risk is age and sex dependent, with intentional injuries peaking from 0 - 4 years of age and unintentional injuries from 4 - 10 years of age, as children are increasingly exposed to risks both inside and outside the home. ${ }^{[3]}$

Childhood injury incidence, mortality and subsequent long-term disability are disproportionately concentrated in low- and middleincome countries (LMICs) such as South Africa (SA). Domestic safety protocols and guidelines are unwritten, unknown or underutilised, compounded by living conditions with greater hazard exposure, lack of parental risk awareness and suboptimal access to paediatric acute trauma care and rehabilitation.

Repeat injuries in childhood (RIC) have been investigated using either hospital attendance data or community-based surveys. Community-based surveys report on injuries for which caregivers have not sought external medical assistance, whereas hospital databased studies report only on injuries requiring treatment and admission. North American and European hospital RIC studies focus on the quantification of 'accident proneness', on the assumption that risk of injury is intrinsic to individuals, with environmental and agent factors being mitigated by policy, legislation and higher standards of living in these regions. However, a systematic review of RIC in low-, middle- and high-income countries by Visser et al. ${ }^{[4]}$ concluded that within populations of injured children are subpopulations with a higher risk of repeat injuries than others.

\section{Objectives}

There is limited evidence regarding agent and environmental factors that predispose children to injury in LMICs. To date, no study has determined the incidence of RIC in SA. The objectives of this study were therefore to: $(i)$ determine the proportion of children presenting with RIC; and (ii) assess whether RIC are associated with (a) agent factors (including aetiology, severity and intent), (b) host factors (including patient age and sex), and (c) environmental factors (including initial discharge method, geographical and domestic location, and census-derived child dependency ratios) as per the Haddon Matrix of Injury (Fig. 1). ${ }^{[5]}$ Transport-related injuries were excluded, as risk factors are likely to be different from domestic RIC.

\section{Methods}

\section{Study setting}

This study was based in the Red Cross War Memorial Children's Hospital Trauma Unit (RCWMCH TU) in the Cape Town metropolitan region of Western Cape Province, SA. Cape Town underwent substantial growth during the study period (1997 - 2003), 


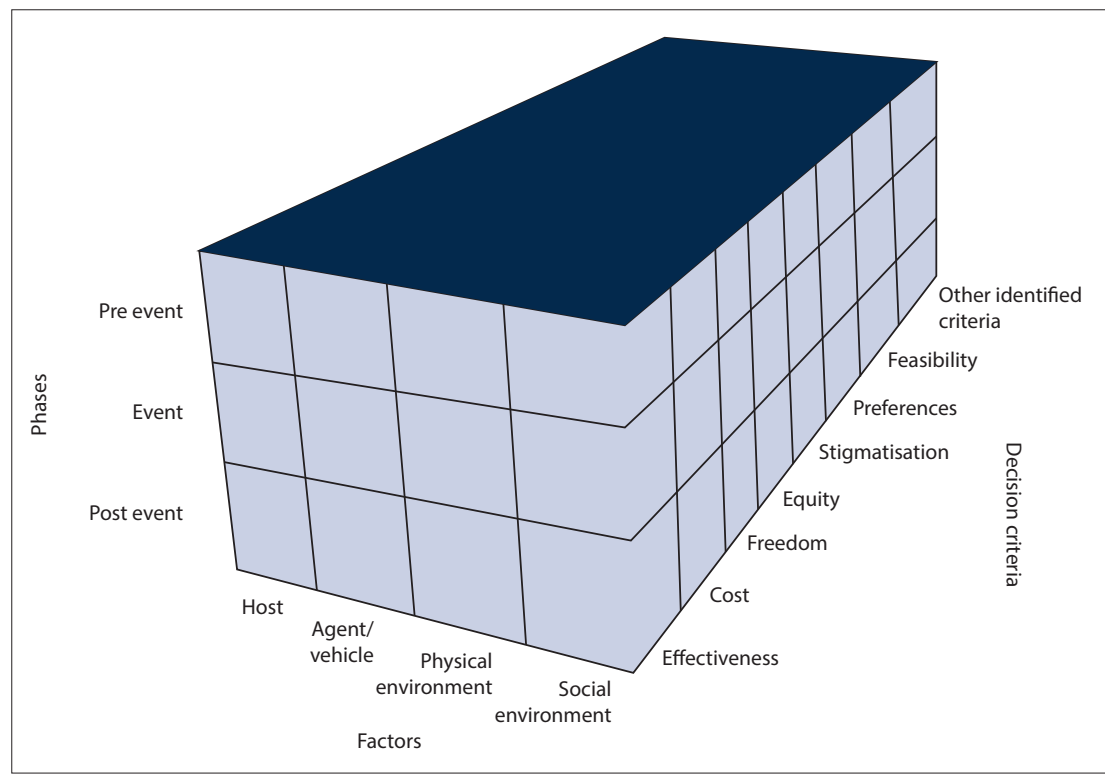

Fig. 1. The Haddon matrix of injury (source: Runyan ${ }^{[5]}$ ).

with a population of 2563095 in 1996 and 4004793 in 2016, approximately two-thirds of the total Western Cape population. ${ }^{[6,7]}$ The majority of patients presenting to the RCWMCH TU live in the Cape Town metropolitan region (Fig. 2).

\section{Study design}

This study was a retrospective cohort analysis of RCWMCH TU data linked to census and mortality data.

Study population, inclusion and exclusion criteria

The study sample consisted of patients who presented to the RCWMCH TU for the first time at age $<10$ years between 1 January 1997 and 30 June 2013 and were discharged alive following initial presentation. Followup tracking for RIC continued until 30 June 2016, with a total study period with followup of 19.5 years. Patients had to be living in the Cape Town metropolitan region at the time of first injury and were assumed to be resident there until the end of the study period.

Only patients who contributed at least 3 years of person-time were included in the study population. Patient-time in days was calculated from the date of first injury presentation and censored at the earliest of the date of the 13th birthday, the date of death as recorded by the Western Cape Provincial Health Data Centre, or the end of the study period on 30 June 2016.

\section{Sample size and selection}

Patients with both intentional and unintentional injuries of any severity (as assessed by RCWMCH TU clinicians) were included. Of $>20$ different first-presentation aetiologies, the top 5 (which together accounted for $>50 \%$ of all injuries) were described and included in the regression analysis. These included falling from a nonheight level, being struck by or against an object or structure, falling from a height level, ingesting a foreign body or having a fluid burn. All transport-related injuries, both first and repeat presentations, were excluded, as transport-related RIC are assumed to have different risk factors to domestic RIC. Patients with poisoning were not included, as they are not treated at the RCWMCH TU.

\section{Data sources and data collection}

Data were included from three sources: (i) hospital data from the RCWMCH TU; (ii) mortality data from the Western Cape Provincial Health Data Centre; and (iii) geographical census data from the South African National Census (2011).

Hospital data were collected prospectively in the RCWMCH TU. Attending clinicians complete patient information sheets after initial examination and investigations. Nurses complete referral information once the patient is discharged.

Injury severity was graded according to the RCWMCH TU Abbreviated Injury Score (AIS): (i) minor injury - patients with minimal or no clinical evidence of injury as assessed by the attending clinician, who can be discharged from the TU directly and who only require advice on future prevention; (ii) moderate injury - patients assessed as having moderate injury by the attending clinician, including all patients with head injury, all patients requiring suturing, all injuries requiring application of plaster of Paris, and all patients requiring admission; and (iii) severe injury - patients who meet the criteria for moderate injury and are assessed by the attending clinician to have severe, life-threatening injuries.

Patient information sheets were uploaded on a monthly basis to an Excel database, version 2010 (Microsoft, USA). Hospital data were then merged with: (i) provincial mortality data to identify patients who had died at or within 3 years of first presentation (therefore requiring exclusion from the study); and (ii) geographical census data using patient addresses to determine suburblevel child dependency ratios (CDRs). The CDR was calculated as: (Total number of children (aged $0-14$ years) in suburb)/ (Total number of adults (aged 15 - 65 years) in suburb) $\times 100$.

Patients were grouped into low, medium and high CDR categories based on tertile cut-off points.

\section{Data management and analysis}

Data were analysed using Excel 2013 (Microsoft, USA), Stata V14 (StataCorp, USA), and ArcMap V10.2.2 (Esri, USA). Residential distance from the RCWMCH TU was calculated using suburb geographical co-ordinates provided by the City of Cape Town. Follow-up visits or repeat presentation $<24$ hours after initial presentation were excluded. Mortality was derived by linking Western Cape Department of Health folder numbers (which are unique patient identifiers) with Department of Home Affairs mortality records. This was done via application through the Western Cape Provincial Health Data Centre. Mortality data included deaths from all causes, both natural and non-natural, that occurred in the Western Cape during the study period.

The primary outcome was the proportion of children with at least 3 years' followup since first injury presentation who experienced a repeat presentation for injury. Secondary outcomes were incidence rates for repeat presentation, by different host, agent and environmental factors. We then used a multilevel Poisson regression model to determine incidence rate ratios associated with the following variables after adjusting for total days in the study: age, sex, injury aetiology, intent (unintentional, self-inflicted or abuse), injury severity (minor, moderate or severe), discharge or transfer location (e.g. home, admission ward, child care agency), health subdistrict of origin, suburb-level 


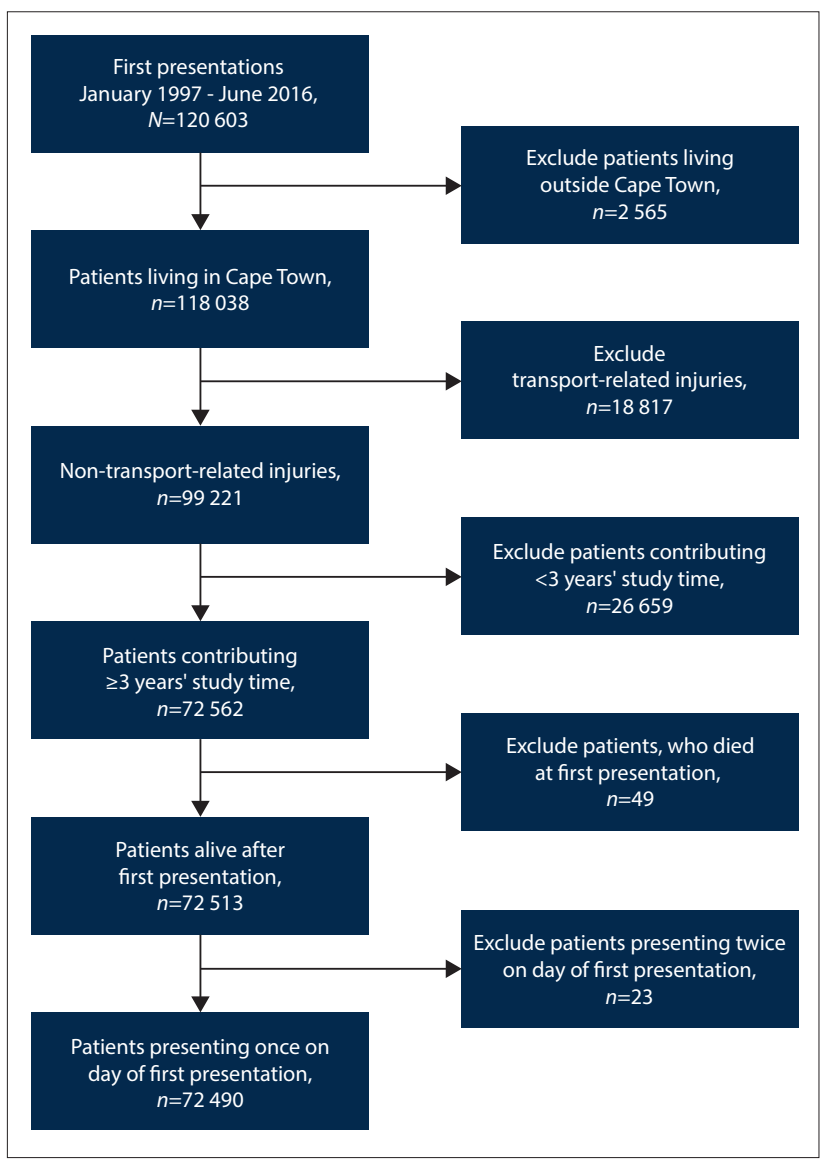

Fig. 2. Study sample flow map.

CDR category, local place of injury (e.g. within or outside the home), and distance from RCWMCH (categorised as $<10 \mathrm{~km}, 10-20 \mathrm{~km}$, $20-30 \mathrm{~km}$ and $>30 \mathrm{~km}$ ).

\section{Ethical considerations and permissions}

The study research protocol was approved by the University of Cape Town's Health Research Ethics Committee (ref. no. 343/2017), which included a waiver of individual consent. Permission was also sought and received from the Western Cape Department of Health Research Committee, the Chief Executive Officer of RCWMCH and the President of ChildSafe.

\section{Results}

Additional figures and tables are available online (http://samj.org.za/ public/sup/14546.pdf).

\section{Repeat injuries}

Over the study period, 72490 of the children who presented to the TU met the inclusion criteria. Most children (63 073; 87\%) presented once, but a substantial minority ( $9417 ; 13 \%)$ presented with RIC (Table 1). A small number (1 970; 3\%) experienced $\geq 3$ injuries. The median (interquartile range (IQR)) time to repeat presentation was $1.8(0.7-3.7)$ years.

\section{Host factors associated with repeat injury}

Repeat presenters were significantly younger at first presentation than single presenters, with a median (IQR) age of $2.7(1.4-5.1) \mathrm{v}$. $3.6(1.7-6.3)$ years $(p<0.001)$. Males comprised $59 \%$ of all patients and $65 \%$ of patients with RIC. Males had a significantly higher incidence rate of RIC at 2.6 (95\% confidence interval (CI) 2.6 2.7) v. 1.9 (95\% CI 1.8 - 2.0) per 100 person-years (py) for females $(p<0.001)$ (Table 2$)$. A significantly greater percentage of males than females had repeat presentations (14\% (95\% CI 14.1 - 14.8) v. $11 \%$ (95\% CI 10.6 - 11.3), respectively), representing a relative percentage difference of $3 \%(p<0.001)$. The adjusted incidence rate ratio (aIRR) for male v. female sex was 1.4 (95\% CI $1.4-1.5 ; p<0.001)$.

\section{Agent factors associated with repeat injury}

Aetiology

RIC rates differed according to aetiology of first injury. Patients presenting with falls from a non-height level were most likely to have a repeat presentation, with $14 \%$ (95\% CI 13.7 - 14.9) doing so, whereas patients presenting with fluid burns were least likely to have a repeat presentation, at 7\% (95\% CI 6.6 - 7.8). In adjusted analysis, only falls from a non-height level remained significantly associated with increased RIC, with aIRR 1.1 (95\% CI 1.0 - 1.1; $p=0.001$ ), compared with all other aetiologies. Patients who first presented with foreign body ingestion or fluid burns were significantly less likely to present with repeat injuries, with aIRRs for RIC of 0.7 (95\% CI 0.7 0.8 ) and 0.6 (95\% CI $0.6-0.7$ ), respectively ( $p<0.001$ for both).

\section{Intentional and unintentional injuries}

Unintentional injuries formed the overwhelming majority of injuries, comprising $95 \%$ of injuries, or up to $99 \%$ when excluding abuse categorised as 'possible' by attending clinicians (Table 1). Intentional injuries were classified as being either due to abuse or self-inflicted. Patients with definitive abuse were significantly less likely to have a repeat presentation, with an aIRR of 0.6 (95\% CI $0.4-0.7 ; p<0.001)$. There was no significant difference in risk of RIC among patients who first presented with self-inflicted v. unintentional injury.

\section{Injury severity}

Overall, $61 \%, 37 \%$ and $2 \%$ of patients first presented with minor, moderate and severe injuries, respectively. Injury severity was inversely associated with RIC risk. Patients with initial minor injuries had the highest rate of RIC, with 2.6 repeat injuries (95\% CI 2.6 - 2.7) per 100 py, whereas rates for patients with moderate and severe injuries were 1.8 repeat injuries $(95 \%$ CI $1.8-1.9)$ per 100 py and 1.2 repeat injuries (95\% CI 1.0 - 1.5) per 100 py, respectively. In adjusted analysis, children with moderate and severe injuries were found to have significantly lower rates of repeat injury than those with minor injuries, with moderate injury patients having an aIRR of 0.9 (95\% CI $0.8-0.9)$ and severe injury patients having an aIRR of 0.7 ( $95 \%$ CI $0.6-0.8$ ), with both being significantly more likely to have a repeat presentation than patients with minor injuries $(p<0.001$ for both).

\section{Environmental factors associated with repeat injury Child dependency ratio}

The CDR, a population ratio measure of children to adults in an area, calculated from the 2011 National Census, was skewed to the left, i.e. a greater number of families had higher ratios of children to adults. The median CDR was similar for single and repeat presenters, at 38.9 (IQR 33.9 - 42.3) and 37.9 (IQR 31.8 - 41.9) children per 100 adults, respectively. In the adjusted analysis, there was no significant association between CDR and risk of RIC.

\section{Discharge method}

Upon discharge from the RCWMCH TU, patients were admitted to wards, discharged with follow-up to the outpatient service, 


\begin{tabular}{|c|c|c|c|}
\hline Variables & $\begin{array}{l}\text { Repeat presenters } \\
(N=9417 ; 12.9 \%)^{*}\end{array}$ & $\begin{array}{l}\text { Single presenters } \\
(N=63073 ; 87.0 \%)^{*}\end{array}$ & $\begin{array}{l}\text { Total } \\
(N=72490 ; 100 \%)^{\dagger}\end{array}$ \\
\hline \multicolumn{4}{|l|}{ Date of first injury, $n(\%)$} \\
\hline $1997-2000$ & $2561(15.1)$ & $14419(84.9)$ & $16980(23.4)$ \\
\hline $2001-2004$ & $2245(14.6)$ & $13158(85.4)$ & $15403(21.33)$ \\
\hline $2005-2008$ & $2261(13.4)$ & $14642(86.6)$ & $16903(23.3)$ \\
\hline $2009-2013^{\ddagger}$ & $2350(10.1)$ & $20854(89.9)$ & $23204(32.0)$ \\
\hline Days in study, median (IQR) & $3032(2155-3886)$ & $2557(1815-3486)$ & $2621(1853-3555)$ \\
\hline \multicolumn{4}{|l|}{ Demographics } \\
\hline Age (years) at first presentation, median (IQR) & $2.7(1.4-5.1)$ & $3.6(1.7-6.3)$ & $3.6(1.6-6.1)$ \\
\hline \multicolumn{4}{|l|}{ Sex, $n(\%)$} \\
\hline Male & $6127(14.4)$ & $36313(85.6)$ & $42440(58.7)$ \\
\hline Female & $3274(10.9)$ & $26592(89.0)$ & $29866(41.3)$ \\
\hline \multicolumn{4}{|l|}{ Top 5 causes of injury, $n(\%)$} \\
\hline Fall from non-height level & $1986(14.3)$ & $11902(85.7)$ & $13888(19.2)$ \\
\hline Struck by or against & $958(13.9)$ & $5920(86.1)$ & $6878(9.5)$ \\
\hline Fall from height level & $867(13.9)$ & $5381(86.1)$ & $6248(8.6)$ \\
\hline Foreign body ingestion & $530(10.8)$ & $4387(89.2)$ & $4917(6.8)$ \\
\hline Fluid burn & $569(7.2)$ & $7357(92.8)$ & $7926(10.9)$ \\
\hline \multicolumn{4}{|l|}{ Injury intent, ${ }^{\varsigma} n(\%)$} \\
\hline \multicolumn{4}{|l|}{ Self-inflicted } \\
\hline Yes & $364(3.9)$ & $2159(3.4)$ & $2523(3.5)$ \\
\hline No & $9053(96.1)$ & $60914(96.6)$ & $69967(96.5)$ \\
\hline \multicolumn{4}{|l|}{ Abuse } \\
\hline Yes & $60(0.6)$ & $757(1.2)$ & $817(1.1)$ \\
\hline Possible & $345(3.7)$ & $2503(4.0)$ & $2848(3.9)$ \\
\hline No & $9011(95.7)$ & $59765(94.8)$ & $68776(95.0)$ \\
\hline \multicolumn{4}{|l|}{ Injury by severity (AIS), $, 9, n$ (\%) } \\
\hline Minor & $6569(69.8)$ & $37850(60.0)$ & $44419(61.3)$ \\
\hline Moderate & $2737(29.1)$ & $24003(38.1)$ & $26740(36.9)$ \\
\hline Severe & $109(1.2)$ & $1215(1.9)$ & $1324(1.8)$ \\
\hline \multicolumn{4}{|l|}{ Discharged or transferred to, $n(\%)$} \\
\hline Home & $6161(65.5)$ & $34957(55.4)$ & $41118(56.7)$ \\
\hline Absconded & $32(0.3)$ & $221(0.4)$ & $253(0.4)$ \\
\hline PHC clinic & $367(3.9)$ & $2185(3.5)$ & $2552(3.5)$ \\
\hline Other hospital & $34(0.4)$ & $286(0.5)$ & $320(0.4)$ \\
\hline RCWMCH outpatients & $2388(25.4)$ & $19012(30.1)$ & $21400(29.5)$ \\
\hline RCWMCH ward & $157(1.7)$ & $1512(2.4)$ & $1669(2.3)$ \\
\hline RCWMCH burns unit & $248(2.6)$ & $4675(7.4)$ & $4923(6.8)$ \\
\hline RCWMCH ICU & $20(0.2)$ & $166(0.3)$ & $186(0.3)$ \\
\hline Child care agency & $5(0.1)$ & $54(0.1)$ & $59(0.1)$ \\
\hline \multicolumn{4}{|l|}{ Location where injury occurred, $n$ (\%) } \\
\hline \multicolumn{4}{|l|}{ Health subdistrict" } \\
\hline Eastern & $50(3.8)$ & $1270(96.2)$ & $1320(1.8)$ \\
\hline Klipfontein & $3573(17.8)$ & $16555(82.3)$ & $20128(27.8)$ \\
\hline Western & $1622(16.1)$ & $8460(83.9)$ & $10082(13.9)$ \\
\hline Tygerberg & $772(12.2)$ & $5546(87.8)$ & $6318(8.7)$ \\
\hline Mitchells Plain & $1497(11.6)$ & $11467(88.5)$ & $12964(17.9)$ \\
\hline Southern & $998(11.5)$ & $7661(88.5)$ & $8659(12.0)$ \\
\hline Northern & $36(5.5)$ & $620(94.5)$ & $656(0.9)$ \\
\hline Khayelitsha & $381(5.1)$ & $7159((94.9)$ & $7540(10.4)$ \\
\hline Unknown & $488(10.1)$ & 4335 (89.9) & $4823(6.7)$ \\
\hline \multicolumn{4}{|l|}{ Place } \\
\hline Own home inside & $5079(53.9)$ & $31839(50.5)$ & $36918(50.9)$ \\
\hline Own home outside & $1633(17.3)$ & $11462(18.2)$ & $13095(18.1)$ \\
\hline Other home inside & $218(2.3)$ & $1618(2.6)$ & $1836(2.5)$ \\
\hline
\end{tabular}




\begin{tabular}{|c|c|c|c|}
\hline Variables & $\begin{array}{l}\text { Repeat presenters } \\
(N=9417 ; 12.9 \%)^{*}\end{array}$ & $\begin{array}{l}\text { Single presenters } \\
(N=63073 ; 87.0 \%)^{*}\end{array}$ & $\begin{array}{l}\text { Total } \\
(N=72490 ; 100 \%)^{\dagger}\end{array}$ \\
\hline Other home outside & $182(1.9)$ & $1527(2.4)$ & $1709(2.3)$ \\
\hline Road or pavement & $229(2.4)$ & $1756(2.8)$ & $1985(2.7)$ \\
\hline School or crèche & $580(6.2)$ & $4841(7.7)$ & $5421(7.5)$ \\
\hline Public place & $592(6.3)$ & $4040(6.4)$ & $4632(6.4)$ \\
\hline Sport & $80(0.9)$ & $453(0.7)$ & $533(0.7)$ \\
\hline Other & $495(5.3)$ & $3006(4.8)$ & $3501(4.8)$ \\
\hline Unknown & $329(3.5)$ & $2531(4.0)$ & $2860(4.0)$ \\
\hline $\mathrm{CDR}, * *$ median (IQR) & $37.9(31.8-41.9)$ & $38.9(33.9-42.3)$ & $38.9(33.5-42.3)$ \\
\hline \multicolumn{4}{|c|}{ Distance $(\mathrm{km})$ from suburb of residence to $\mathrm{RCWMCH}^{+\dagger}$} \\
\hline \multicolumn{4}{|l|}{$>30$} \\
\hline \multicolumn{4}{|l|}{$20-30$} \\
\hline \multicolumn{4}{|l|}{$10-20$} \\
\hline \multicolumn{4}{|l|}{$0-10$} \\
\hline \multicolumn{4}{|c|}{ 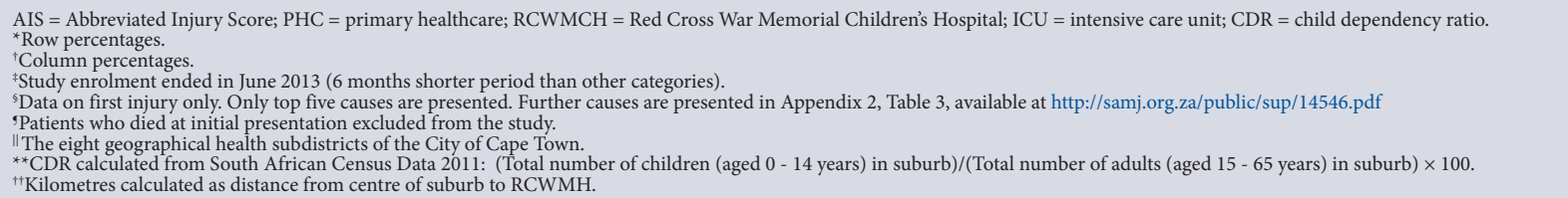 } \\
\hline
\end{tabular}

down-referred to other hospitals or primary healthcare facilities, or discharged directly home. Patients who were discharged directly home had the highest incidence rates of repeat injury, at 2.6 (95\% CI 2.5 - 2.7) per 100 py.

Among patients referred internally in the hospital, those admitted to the ICU had the highest rate of repeat presentation, 2.3 (95\% CI 1.6 - 3.2) per 100 py. Patients admitted to the burns unit had the lowest rates of repeat presentations, 0.8 (95\% CI $0.7-0.8)$ per 100 py. In the adjusted analysis, patients admitted to the ICU were significantly more likely than those discharged home to have repeat presentations, with an aIRR of 1.5 (95\% CI $1.1-2.1 ; p=0.024)$. This may be due to long-term disability after discharge from the ICU, such as is seen in cerebral palsy, resulting in neurological fallout or musculoskeletal instability due to early insults to the developing brain. Patients referred to the burns unit had the lowest risk of RIC, with an aIRR of 0.5 (95\% CI $0.5-0.6 ; p<0.001)$.

\section{Geospatial factors}

First-presentation injury aetiology differed by subdistrict, with fluid burn injuries predominating in the Northern, Eastern and Tygerberg subdistricts, and fall injuries predominating in Southern, Western, Mitchells Plain, Khayelitsha and Klipfontein (Fig. 3).

Patients living closest to RCWMCH TU recorded higher rates of repeat presentation, with an aIRR of 3.8 (95\% CI 2.9 - 4.9) for patients living $<10 \mathrm{~km} \mathrm{v}$. $>30 \mathrm{~km}$ away $(p<0.001)$. The eight health subdistricts in the Cape Town metropole displayed differing rates of repeat presentation, even when adjusting for proximity to the RCWMCH TU. Klipfontein subdistrict, in which the TU is located, recorded the highest rate of repeat presentations, at 3.3 (95\% CI 3.2 - 3.4) per 100 py.

The Khayelitsha and Eastern subdistricts, the centre points of which are located furthest from RCWMCH TU, recorded the lowest rates, at 0.8 (95\% CI 0.7 - 0.8 ) and 0.7 (95\% CI 0.5 - 0.9) per 100 py, respectively. However, these patients may have been more likely to present to other facilities in their referral zones for their repeat presentations.

When adjusting for all other variables including distance from facility, Klipfontein patients demonstrated the highest aIRR for repeat presentation, at 2.4 (95\% CI $2.1-2.8 ; p<0.001)$. Local place of first

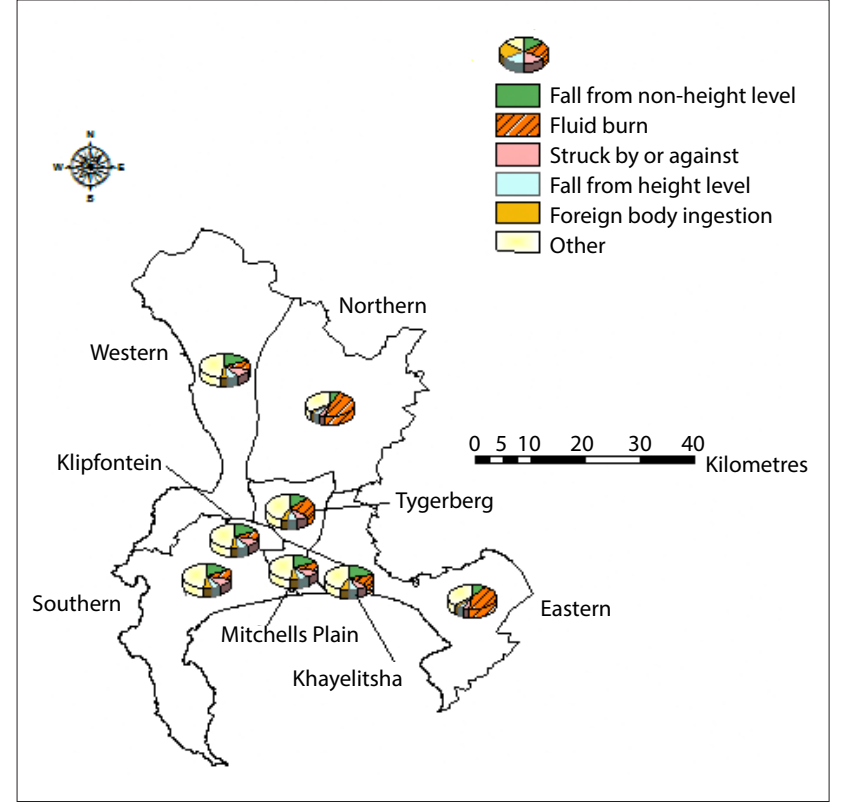

Fig. 3. Injury aetiology at first presentation by health subdistrict.

injury was similar for both single and repeat presenters, with over half of all injuries occurring in the child's own home, $20 \%$ outside the child's own home, and $\sim 7 \%$ at a school or crèche.

Children who lived further away from RCWMCH TU tended to have more serious injuries, in keeping with the facility's status as a tertiary-level trauma unit. This relationship was similar for both single and repeat presenters; however, patients who had repeat presentations tended to live closer to RCWMCH TU than single presenters across all injury severity categories (Fig. 4).

\section{Discussion}

This study demonstrated a substantial burden of repeated childhood injuries at the RCWMCH TU. These results concur with RIC metaanalyses showing that within cohorts of injury victims are 'a sub- 


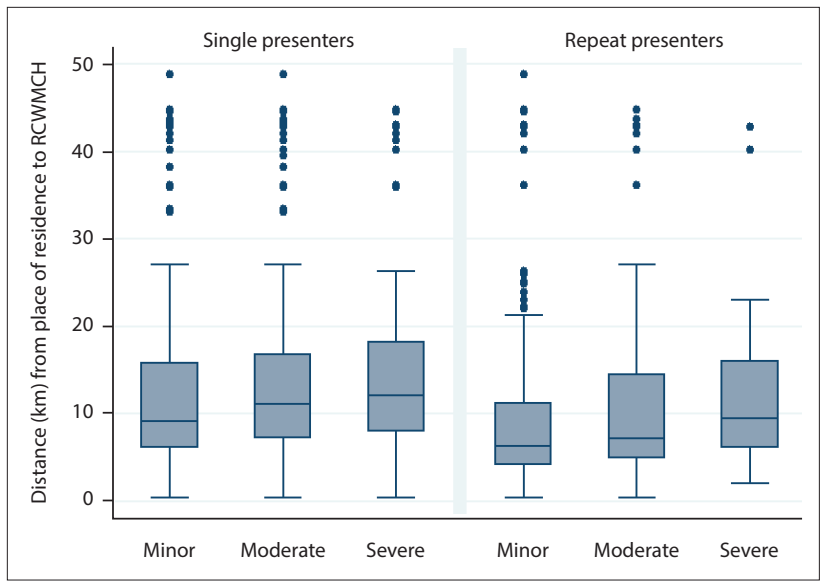

Fig. 4. Box plot of distance of place of residence from RCWMCH by severity of first injury, for single and repeat presenters. (RCWMCH $=$ Red Cross War Memorial Children's Hospital.)

group of patients at increased risk for repeat injuries, such that they present with greater frequency than that which would be expected due to chance alone. ${ }^{[8]}$

\section{Gender}

In keeping with previous studies and global reports, males were significantly more likely than females to re-present to the $\mathrm{TU} .^{[1]}$ Understandably, patients who presented multiple times were more likely to have a first presentation earlier in life. This may suggest a 'riskier' environment, with a preponderance of frequent and earlier injuries in individuals exposed to increasing levels of social deprivation. Although patients first presenting earlier in life would have had more time to re-present, this was controlled for in the Poisson regression analysis.

\section{Subdistricts}

Percentages for repeat presentation differed substantially across health subdistricts in the Cape Town metropolitan area. Subdistricts closer to RCWMCH such as Klipfontein and Western recorded higher percentages of repeat presentation, possibly owing to geographical referral zones in the metropole. When adjusting for all other variables including distance from facility, injury victims from Klipfontein remained most likely to have repeat presentations.

\section{Intentional v. non-intentional}

The finding of an inverse relationship between definitive cases of abuse and RIC should be interpreted within the context of SA legislation - all healthcare practitioners suspicious of non-accidental injury in children are obligated to report suspected abuse to the relevant authorities. An inverse relationship suggests one of two possibilities: that recognition of abuse by healthcare professionals may mitigate the recurrence thereof, or that children with recognised index non-accidental injuries are not brought back to the same facility, or to any facility at all, at repeat occurrences.

\section{Injury types}

In the adjusted analysis, patients with falls from non-height level injuries at first presentation were most likely to have repeat presentations. Fall-type injuries predominated overall, with $>25 \%$ of first-time injuries being due to falls from either height or nonheight levels. Children suffering fluid burn injuries were significantly less likely to have a repeat injury. Burn injuries tend to require long admissions, with multiple opportunities for burn prevention education. RCWMCH also conducts injury prevention training sessions upon discharge, which include specific interventions to prevent repeat household fires (unpublished). This post-discharge prevention education is therefore either highly effective, or not needed at all - this requires further exploration. Although sportrelated injuries represented a small number of patients $(n=533)$, there was a significant risk for repeat presentation, with an aIRR of 1.6 (95\% CI $1.3-2.0 ; p<0.001)$.

\section{Injury severity}

In the literature it is reported that major injuries resulting in permanent comorbidity, such as musculoskeletal or neurocognitive disabilities, can predispose children to subsequent (especially fall-related) injuries, and such injuries are therefore posited as a significant risk factor for repeat injuries. ${ }^{[9]}$ However, in the present study, lower-severity injuries were associated with repeat presentations. In SA, families experiencing major injury are likely to belong to communities in which health-seeking behaviour and ease of access to care are poor and may therefore experience multiple subsequent injuries without re-presenting to hospital for care. Permanent disability may also preclude normal childhood activities and result in fewer opportunities for further injury.

\section{Study limitations}

This study was conducted at RCWMCH TU and therefore does not capture patient attendance information from other facilities in Cape Town, although patients may have presented elsewhere during the study period or migrated out of the province. It is also not possible to directly measure pertinent patient or household-level information such as quality of caregiver supervision or family size or structure, hence the use of an ecological-level, census-derived CDR.

The variable most strongly associated with repeat presentation was residence within a $10 \mathrm{~km}$ radius of the RCWMCH TU. These patients had repeat presentations at $3.8(95 \%$ CI $2.9-4.9)$ times the rate of those living $>30 \mathrm{~km}$ away $(p<0.001)$. As RCWMCH is a tertiary referral unit, patients from further away tended to have more severe injuries. There is likely to be an element of confounding between distance and severity, as patients from further away are more likely to present to their local clinics for minor injuries.

The CDR proved unhelpful in differentiating areas prone to repeat presentations. The use of census-level data to make assumptions regarding the family context of children presenting to the trauma unit may have introduced an element of ecological fallacy, with high-CDR households presenting from low-CDR areas. This study was not able to retrospectively determine patient comorbidity, quality of caregiver supervision, family size or structure.

The comparison of repeat injury rates across the entire Cape metropolitan area was hampered by use of single-facility data, which is likely to have led to an undercounting of total RIC. New facilities that opened during the study period may also have resulted in changes to referral pathways.

\section{Conclusions}

Van As and Stein ${ }^{[10]}$ note that childhood injuries are "less commonly due to intentional abuse and maltreatment, than the consequence of failure to be aware of child injury and appreciate the need for appropriate intervention. This awareness can be depicted by preventable contexts and events, as illustrated in the agenthost-environment Haddon matrix ${ }^{[5,11]}$ (Fig. 1), further elaborated by Runyan ${ }^{[5]}$ to include possible countermeasures. First injury presentations are therefore an opportunity to provide secondary prevention education to high-risk populations. ${ }^{[8,12]}$ 
Table 2. Absolute and adjusted incidence rate ratios for repeat injury presentation to the RCWMCH Trauma Unit, for different child, injury and environmental characteristics from January 1997 to June 2016 using Poisson regression analysis

\begin{tabular}{|c|c|c|c|c|c|c|}
\hline \multirow[b]{2}{*}{ Source } & \multirow[b]{2}{*}{ Variables } & \multicolumn{2}{|c|}{$\begin{array}{l}\text { Crude absolute } \\
\text { incidence rate }\end{array}$} & \multicolumn{3}{|c|}{ Final model } \\
\hline & & $\begin{array}{l}\text { Absolute } \\
\text { incidence rate } \\
\text { (/100 py) }\end{array}$ & $95 \%$ CI & $\begin{array}{l}\text { Adjusted } \\
\text { incidence } \\
\text { rate ratio }\end{array}$ & $p$-value & $95 \% \mathrm{CI}$ \\
\hline \multirow[t]{4}{*}{ Demographics } & Reference age: $<1$ year & - & - & - & - & - \\
\hline & Age (years) at first presentation & - & - & $0.9^{*}$ & $<0.001$ & $0.9-0.9$ \\
\hline & Reference: female & 1.9 & $1.8-2.0$ & - & - & - \\
\hline & Male sex & 2.6 & $2.6-2.7$ & 1.4 & $<0.001$ & $1.4-1.5$ \\
\hline \multirow[t]{6}{*}{ Injury by cause $^{\dagger}$} & Reference: All other aetiologies & - & - & - & - & - \\
\hline & Fall from non-height level & 2.7 & $2.6-2.8$ & 1.1 & 0.001 & $1.0-1.1$ \\
\hline & Struck by or against & 2.6 & $2.4-2.7$ & 1.0 & 0.451 & $0.9-1.0$ \\
\hline & Fall from height level & 2.5 & $2.3-2.6$ & 1.0 & 0.529 & $0.9-1.1$ \\
\hline & Foreign body ingestion & 1.8 & $1.7-1.9$ & 0.7 & $<0.001$ & $0.7-0.8$ \\
\hline & Fluid burn & 1.1 & $1.0-1.2$ & 0.6 & $<0.001$ & $0.6-0.7$ \\
\hline \multirow[t]{3}{*}{ Injury by intent } & Reference: Unintentional & - & - & - & - & - \\
\hline & Self-inflicted & 2.2 & $2.0-2.4$ & 1.0 & 0.253 & $0.9-1.0$ \\
\hline & Abuse & 1.6 & $1.5-1.8$ & 0.6 & $<0.001$ & $0.4-0.7$ \\
\hline \multirow[t]{3}{*}{ Injury by severity } & Reference: Minor & 2.6 & $2.6-2.7$ & - & - & - \\
\hline & Moderate & 1.8 & $1.8-1.9$ & 0.9 & $<0.001$ & $0.8-0.9$ \\
\hline & Severe & 1.2 & $1.0-1.5$ & 0.7 & $<0.001$ & $0.6-0.8$ \\
\hline \multirow[t]{9}{*}{ Discharge or transfer location } & Reference: Home & 2.6 & $2.6-2.7$ & - & - & - \\
\hline & Absconded & 2.1 & $1.5-2.9$ & 0.8 & 0.228 & $0.6-1.1$ \\
\hline & PHC clinic & 2.4 & $2.2-2.7$ & 1.0 & 0.463 & $0.9-1.1$ \\
\hline & Other hospital & 1.7 & $1.2-2.3$ & 0.8 & 0.070 & $0.6-1.0$ \\
\hline & RCWMCH outpatients & 2.2 & $2.1-2.2$ & 0.9 & 0.001 & $0.9-1.0$ \\
\hline & RCWMCH ward & 1.5 & $1.3-1.8$ & 0.7 & $<0.001$ & $0.6-0.9$ \\
\hline & RCWMCH burns unit & 0.8 & $0.7-0.8$ & 0.6 & $<0.001$ & $0.5-0.6$ \\
\hline & RCWMCH ICU & 2.3 & $1.6-3.2$ & 1.5 & 0.024 & $1.1-2.1$ \\
\hline & Child care agency & 1.1 & $0.4-2.6$ & 0.6 & 0.266 & $0.3-1.5$ \\
\hline \multirow[t]{9}{*}{ Health subdistrict ${ }^{\ddagger}$} & Reference: Khayelitsha & 0.8 & $0.7-0.8$ & - & - & - \\
\hline & Eastern & 0.7 & $0.5-0.9$ & 1.1 & 0.573 & $0.8-1.4$ \\
\hline & Northern & 1.0 & $0.8-1.4$ & 1.8 & $<0.001$ & $1.3-2.4$ \\
\hline & Tygerberg & 2.1 & $1.9-2.2$ & 1.8 & $<0.001$ & $1.6-2.1$ \\
\hline & Klipfontein & 3.3 & $3.2-3.4$ & 2.4 & $<0.001$ & $2.1-2.8$ \\
\hline & Southern & 2.0 & $1.9-2.1$ & 2.0 & $<0.001$ & $1.7-2.3$ \\
\hline & Western & 2.9 & $2.8-3.1$ & 2.3 & $<0.001$ & $2.0-2.7$ \\
\hline & Mitchells Plain & 2.0 & $1.9-2.1$ & 2.4 & $<0.001$ & $2.1-2.7$ \\
\hline & Unknown & 2.7 & $2.5-3.0$ & 1.8 & $<0.001$ & $1.5-2.2$ \\
\hline \multirow[t]{10}{*}{ Place } & Reference: School or crèche & 2.1 & $1.9-2.2$ & - & - & - \\
\hline & Inside own home & 2.4 & $2.3-2.4$ & 1.2 & $<0.001$ & $1.1-1.3$ \\
\hline & Outside own home & 2.3 & $2.2-2.4$ & 1.1 & 0.048 & $1.0-1.2$ \\
\hline & Inside other home & 2.0 & $1.8-2.3$ & 1.1 & 0.450 & $0.9-1.2$ \\
\hline & Outside other home & 2.2 & $1.9-2.4$ & 1.1 & 0.398 & $0.9-1.2$ \\
\hline & Road or pavement & 2.3 & $2.1-2.6$ & 1.1 & 0.229 & $1.0-1.3$ \\
\hline & Public place & 2.4 & $2.3-2.6$ & 1.1 & 0.023 & $1.0-1.3$ \\
\hline & Sport & 3.5 & $2.9-4.2$ & 1.6 & $<0.001$ & $1.3-2.0$ \\
\hline & Other & 2.4 & $2.3-2.6$ & 1.2 & 0.013 & $1.0-1.3$ \\
\hline & Unknown & 2.1 & $1.9-2.3$ & 1.1 & 0.326 & $0.9-1.2$ \\
\hline \multirow[t]{3}{*}{$\mathrm{CDR}^{\varsigma}$} & Reference: Low & 3.4 & $3.3-3.5$ & - & - & - \\
\hline & Medium & 1.8 & $1.8-1.9$ & 0.9 & 0.007 & $0.9-1.0$ \\
\hline & High & 2.2 & $2.1-2.3$ & 0.8 & 0.288 & $0.5-1.2$ \\
\hline \multirow{4}{*}{$\begin{array}{l}\text { Distance }(\mathrm{km}) \text { from suburb of } \\
\text { residence to RCWMCH }\end{array}$} & Reference: $>30$ & 0.7 & $0.5-0.9$ & - & - & - \\
\hline & $20-30$ & 0.8 & $0.7-0.9$ & 2.4 & $<0.001$ & $1.7-3.2$ \\
\hline & $10-20$ & 1.6 & $1.6-1.7$ & 2.4 & $<0.001$ & $1.8-3.1$ \\
\hline & $0-10$ & 3.1 & $3.0-3.2$ & 3.8 & $<0.001$ & $2.9-4.9$ \\
\hline
\end{tabular}

py = person-years; $\mathrm{CI}=$ confidence interval; $\mathrm{PHC}=$ primary healthcare; $\mathrm{RCWMCH}=$ Red Cross War Memorial Children's Hospital; $\mathrm{ICU}=$ intensive care unit; $\mathrm{CDR}=$ child dependency ratio. * Refers to adjusted incidence rate ratio, per year increase in age.

'Data on first injury only. Only top five causes are presented. Further causes are presented in Appendix 2, Table 3, available at http://samj.org.za/public/sup/14546.pdf

*The eight geographical health subdistricts of the City of Cape Town.

${ }^{\circ} \mathrm{CDR}$ calculated from South African Census Data 2011: (Total number of children (aged 0 - 14 years) in suburb)/(Total number of adults (aged $15-65$ years) in suburb) $\times 100$ 'Kilometres calculated as distance from centre of suburb to RCWMH. 
The results of this study confirm that agent, host and environmental factors are relevant in determining risk for repeat injuries in children. Healthcare practitioners are therefore well placed to identify patients at greater risk of repeat injury and institute appropriate pre-discharge health promotion. Our findings suggest that post-injury health promotion activities should not exclude patients who present with minor injuries, and that targeted education is indicated for specific injuries, including those due to non-height falls and those sustained while playing sport. Areas with high rates of repeat injuries require further community-based research to determine specific household factors that predispose children to repeat injury.

Declaration. The research for this study was done in partial fulfilment of the requirements for SMP's MMed (Public Health Medicine) degree at the University of Cape Town.

Acknowledgements. The authors express their gratitude for being granted permission to use the ChildSafe Paediatric Trauma Surveillance System for all data on children presenting to RCWMCH.

Author contributions. SMP conceptualised the study, performed the data collection and wrote the article with the assistance of M-AD and ABvA. Funding. None.

Conflicts of interest. None.
1. World Health Organization. World report on childhood injury prevention. Inj Prev 2008;14(1):69. https://doi.org/10.1136/ip.2007.018143

2. Peterson L, Brown D. Integrating childhood injury and abuse-neglect research: Common histories 2. Peterson L, Brown D. Integrating childhood injury and abuse-neglect research: Common histories
etiologies and solutions. Psychol Bull 1994;116(2):293-315. https://doi.org/10.1037/00332909.116.2.293

3. World Health Organization. Violence and injury prevention: Child injuries. 2017. http://www.who. int/violence_injury_prevention/child/injury (accessed 4 April 2017).

4. Visser E, Pijl YJ, Stolk RP, Neeleman J, Rosmalen JG. Accident proneness, does it exist? A review and meta-analysis. Accid Anal Prev 2007;39(3):556-564. https://doi.org/10.1016/j.aap.2006.09.012 . Runyan CW. Using the Haddon matrix: Introducing the third dimension. Inj Prev 2015;21(2):126130. https://doi.org/10.1136/ip.4.4.302rep

6. City of Cape Town, Strategic Development Information and GIS Department. Census 2011 trends and changes over a 10 year period. December 2012. http://resource.capetown.gov.za/ documentcentre/Documents/Maps\%20and\%20statistics/2011_Census_Cape_Town_Profile_ Change_from_2001-2011.pdf (accessed 20 June 2018).

7. City of Cape Town. Socio-economic profile of the City of Cape Town. 2016. https://www.westerncape. 7. City of Cape Town. Socio-economic profile of the City of Cape Town. 2016. https://www.westerncape.
gov.za/assets/departments/treasury/Documents/Socio-economic-profiles/2016/City-of-Cape-Town/ city_of_cape_town_2016_socio-economic_profile_sep-lg.pdf (accessed 20 June 2018).

8. Dorrington RE, Bradshaw D, Laubscher R, Nannan N. Rapid Mortality Surveillance Report. Cape Town: South African Medical Research Council, 2014. https://www.samrc.ac.za/sites/default/files/ files/2016-07-04/RapidMortalitySurveillanceReport2014.pdf (accessed 3 April 2017).

9. Ruiz-Casares M. Unintentional childhood injuries in sub-Saharan Africa: An overview of risk and protective factors. J Health Care Poor Underserved 2009;20(4A):51-67. http://doi.org/10.1353/ hpu. 0.0226

10. Van As S, Stein DJ. Child safety: A neglected priority. World J Pediatr 2010;6(4):293-295. https://doi. org/10.1007/s12519-010-0229-5

11. Van As S, Naidoo S. Paediatric Trauma and Child Abuse. Cape Town: Oxford University Press, 2008.

12. Department of Social Development and Department of Women, Children and People with Disabilities, South Africa, and UNICEF (United Nations International Children's Emergency Fund). Children with Disabilities in South Africa: A Situation Analysis. Pretoria: DSD, DWCPD and UNICEF, July 2012. http://www.women.gov.za/images/SITAN-Disability-Exec-Summary-low-res. pdf (accessed 5 May 2017).

Accepted 19 May 2020. 